\title{
ANÁLISE DOS PROCESSOS UTILIZADOS NA ADMINISTRAÇÃO DE MATERIAIS DE MICROEMPRESAS
}

\author{
Aline Akemi Iamashita ${ }^{1}$ \\ Hercílio Costa Filho ${ }^{2}$
}

IAMASHITA, A. A.; COSTA FILHO. H. Análise dos processos utilizados na administração de materiais de microempresas do município de Alto Paraná - Pr. Rev. Ciênc. Empres. UNIPAR, Umuarama, v. 20, n. 2, p. 255-273, jul./dez. 2019.

RESUMO: Uma boa gestão de estoques é importante para reduzir os custos e aumentar os lucros, já que mantê-los na quantidade correta garante o atendimento da demanda e diminui o capital investido. Com base nesta visão e em teorias de autores como Dias (2009), Francischini e Gurgel (2009) e Gonçalves (2004), o objetivo deste trabalho consiste em analisar os processos, ferramentas e ações de administração de materiais utilizadas por microempresas de uma cidade de pequeno porte. $\mathrm{O}$ método utilizado configurou-se por meio de uma pesquisa descritiva de natureza qualitativa. Para coleta dos dados foi aplicado um questionário com vinte e três perguntas de natureza dissertativa a gestores de empresas sobre a maneira como administram seus recursos materiais. A análise foi feita por agrupamento de semelhança de respostas. O objetivo da pesquisa foi atingido, visto ter sido possível observar que as empresas pesquisadas utilizam de forma modesta, mas com alguma eficácia os métodos e ferramentas preconizados como adequados pelas teorias abordadas. No entanto, alguns métodos e ferramentas ainda poderiam ser adotados para gerar maior eficácia da gestão dos recursos materiais destas organizações.

PALAVRAS-CHAVE: Administração de materiais; Gestão de estoques; Microempresas.

\section{ANALYSIS OF THE MATERIAL MANAGEMENT PROCESSES USED IN MICROENTERPRISES}

\footnotetext{
ABSTRACT: Good inventory management is important to reduce costs and increase profits, since the right amount of inventory ensures that demand can be met while capital invested is decreased. Based on this view and on theories of

DOI: $10.25110 /$ receu.v20i2.7643

${ }^{1}$ Administradora, especialista em MBA de Auditoria, Controladoria e Gestão Financeira pela Fundação de Apoio à UNESPAR - PR. E-mail: alineakemi95@hotmail.com.

${ }^{2}$ Mestre em Administração pela FPL, Professor da Universidade Paranaense - UNIPAR, Unidade universitária de Paranavaí - PR. E-mail: herciliohcf@gmail.com
} 
authors such as Dias (2009), Francischini and Gurgel (2009), and Gonçalves (2004), the objective of this paper is to analyze the material management processes, tools and actions used by microenterprises in a small city. The study used a descriptive research of a qualitative nature. Data was collected through a questionnaire with twenty-three questions, applied to business managers on how they manage their material resources. The data was analyzed by the grouping of similar answers. The objective of the research was achieved, since it was possible to note that the surveyed companies have a modest but somewhat effective use of methods and tools recommended as adequate by the theories approached. However, some methods and tools could further be adopted to make the material resource management in those organizations more effective.

KEYWORDS: Material management; Inventory management; Microbusinesses.

\section{ANÁLISIS DE LOS PROCESOS UTILIZADOS EN LA ADMINISTRACIÓN DE MATERIALES DE MICROEMPRESAS}

RESUMEN: La buena gestión de inventario es importante para reducir los costes y aumentar las ganancias, ya que mantenerlos en la cantidad correcta asegura que se satisfaga la demanda y se reduzca el capital invertido. Basado en esta visión y en teorías de autores como Dias (2009), Francischini y Gurgel (2009) y Gonçalves (2004), el objetivo de esa investigación ha sido analizar los procesos, herramientas y acciones de gestión de materiales utilizados por las microempresas en una ciudad pequeña. El método utilizado se configuró mediante una investigación descriptiva de naturaleza cualitativa. Para la recopilación de datos, se aplicó un cuestionario con veintitrés preguntas de naturaleza ensayo a gestores de empresas sobre cómo administran sus recursos materiales. El análisis se realizó agrupando la similitud de las respuestas. El objetivo de la investigación se logró, ya que fue posible observar que las empresas investigadas utilizan modestamente, pero con cierta eficacia, los métodos y herramientas recomendados como adecuados por las teorías abordadas. Sin embargo, algunos métodos y herramientas aún podrían adoptarse para hacer mayor eficacia de la gestión de los recursos materiales de esas organizaciones.

PALABRAS CLAVE: Gestión de materiales; Gestión de inventario; Microempresas. 


\section{INTRODUÇÃO}

As empresas visam aumentar o seu retorno sobre o valor investido em equipamentos, capital de giro, estoques e outros recursos alocados no empreendimento. Os estoques, por si só, não oferecem retorno para a empresa, já que um grande volume de estoques não significa grandes vendas. $\mathrm{O}$ valor aplicado ajuda na movimentação de materiais, fazendo com que sempre se tenha os produtos para atender a demanda, mas nas quantidades corretas, minimizando o total de capital aplicado nos estoques (DIAS, 2009).

Segundo Gonçalves (2004), conhecer os conceitos sobre a administração de materiais é de suma importância para aumentar a produtividade, diminuir os custos e aumentar a competitividade das empresas. Como exemplo, cabe o reconhecimento de que é preciso comprar uma quantidade economicamente correta, nem muito que resulte em despesas extraordinárias de manutenção, nem pouco que falte produtos para a produção ou entrega aos clientes (VIANA, 2006).

A partir das informações apresentadas sobre a administração de materiais observa-se a importância dos estoques para o resultado financeiro das empresas. E com base na relevância da gestão dos estoques para as organizações, este estudo tem o objetivo de analisar os processos, ferramentas e ações de administração de materiais utilizadas por microempresas do município de Alto Paraná, cidade de pequeno porte e com comércio modesto situada na região noroeste do Paraná.

Esse estudo justifica a sua importância por auxiliar no aproveitamento das informações coletadas, que contribuem para as tomadas de decisões dos gestores das microempresas em relação à administração de materiais, com o intuito de melhorar a forma como estão gerenciando seus materiais para reduzir custos e conseguir atender à demanda. Ao analisar como as empresas gerenciam seus materiais hoje, se torna possível identificar se há algum problema na gestão e optar pela mudança de algumas atitudes para aumentar os lucros.

Ademais, o estudo ajuda os acadêmicos na tomada de conhecimento sobre o processo de administração de materiais, bem como se torna material de auxílio para pesquisas que podem ser realizadas futuramente, contribuindo com os gestores ao evidenciar a importância de uma boa administração de materiais.

\section{REVISÃO BIBLIOGRÁFICA}

\subsection{Administração de materiais}

A administração de materiais pode ser definida como um conjunto de planejamento, organização, direcionamento e gestão das atividades relacionadas à aquisição de materiais para a construção de um estoque, desde a sua fabricação 
ou compra para revenda, até o consumo final (VIANA, 2006).

Possuir uma administração de materiais bem estruturada resulta em vantagens competitivas em relação aos demais concorrentes, devido à redução de custos, diminuição dos investimentos em estoques, melhores condições de compras por meio de negociações com os fornecedores, além de clientes e consumidores satisfeitos com os produtos oferecidos (GONÇALVES, 2004).

É imprescindível que as empresas administrem seus materiais sabiamente para que seu estoque possa atender toda a demanda e que o mesmo não fique saturado e inativo, já que com a quantidade correta, as empresas conseguem atingir um dos seus principais objetivos, que é aumentar o retorno sobre o dinheiro investido (DIAS, 2009).

A administração de materiais começa desde a escolha de um bom fornecedor, do recebimento do produto, estocagem adequada, até chegar ao consumidor final atendendo a sua necessidade na quantidade, qualidade e tempo adequados (MARTINS; ALT, 2009).

Segundo Francischini e Gurgel (2009), uma das estratégias para a administração de materiais acontece por meio da implantação de um programa de gestão com objetivos financeiros e administrativos. Dessa forma, é possível eliminar itens parados, acabando com as causas de existir itens no estoque sem uso para produzir ou vender. Assim, se reduz os investimentos feitos em estoques, sem prejudicar a produção e o atendimento aos clientes, além de reduzir consideravelmente as perdas de materiais que ocorrem na logística industrial por meio de técnicas de movimentação e acondicionamento visando atender aos pedidos dos clientes e reduzindo o custo de embalagens dos materiais ao utilizar formas de movimentação e abastecimento da linha de produção com métodos mais eficazes.

\subsection{Previsão de demanda e compras}

Conforme aponta Dias (2009) para uma boa previsão de demanda é necessário um sistema integrado que seja desenvolvido conforme as características de vendas e a distribuição dos recursos financeiros de cada empresa. Assim ela poderá ser bem-sucedida podendo analisar e interpretar prontamente as informações referentes às suas atividades para saber quando, quanto e o quê comprar de forma mais racional possível. Obter a quantidade adequada no tempo errado não trará benefícios, é preciso equilíbrio.

Determinar a demanda futura tanto de bens quanto de serviços é primordial para que seja elaborado um plano de trabalho que possa dimensionar as capacidades dos equipamentos, recursos financeiros, mão-de-obra disponível e as quantidades de materiais necessários para a produção de bens e/ou serviços (GONÇALVES, 2004). A finalidade de toda essa previsão é diminuir a incerteza, 
para conhecer o máximo das condições que dominarão o futuro e assim tomar a decisão certa no presente. Mesmo não sendo possível eliminar a incerteza, é preciso elaborar as previsões de forma mais assertiva possível (VIANA, 2006).

Segundo Francischini e Gurgel (2009), a precisão da previsão de consumo resulta em mais informações para o administrador tomar decisões corretas sobre a quantidade de estoque que deve manter para atender seus clientes. $\mathrm{O}$ consumo real dos itens pode ser baseado nos padrões básicos ao longo do tempo, que eventualmente serão calculados por métodos de previsão e por variáveis diversas, que são praticamente impossíveis de prever.

De acordo com Arnold (2006), as técnicas de previsão podem ser classificadas em qualitativas, extrínsecas e intrínsecas. As qualitativas são subjetivas, geralmente utilizadas para prever tendências e demanda potencial de determinados produtos para um longo tempo. Já as extrínsecas se baseiam em indicadores externos que influenciam na demanda dos produtos da empresa. E, por último, as intrínsecas que utilizam dados históricos e que, na maioria das vezes, são registrados por um sistema e são de fácil acesso. Essa técnica supõe que o que aconteceu no passado tenderá a acontecer de forma semelhante no futuro.

$\mathrm{Na}$ categoria das técnicas intrínsecas, está o método do último período, que segundo Dias (2009), é o mais simples, pois utiliza o valor do período anterior como previsão para o próximo. No entanto, não é o mais adequado devido às flutuações que existem na demanda.

Outro método que se baseia em dados históricos é a média móvel. Arnold (2006) afirma ser fácil fazer previsões dessa forma, já que é realizada uma média de determinado período anterior baseada na demanda real dele.

No método da média móvel ponderada, as quantidades dos períodos mais próximos recebem um peso maior em relação aos demais, que são valores decrescentes do mais recente ao mais antigo (DIAS, 2009). Assim, cada empresa deve analisar qual o melhor método de previsão de demanda para implantá-lo buscando a maior assertividade possível.

A função de compras é muito importante para uma empresa, pois comprar bem é uma forma de reduzir custos. Por esse motivo é necessário verificar os prazos, a qualidade do produto, os preços e o volume que será comprado. O outro fator, tão importante quanto estes, é o bom relacionamento com os fornecedores, verificando seu potencial, suas instalações e seus produtos, além de manter um cadastro completo deles, com cotações realizadas periodicamente (DIAS, 2009).

Cada empresa organiza o seu setor de compras de acordo com as suas necessidades. Pode ser centralizada, onde todas as aquisições são feitas em um único lugar, tendo como benefícios maiores vantagens e descontos dos fornecedores devido à quantidades maiores de pedidos, além da qualidade padrão dos materiais comprados, uma maior especialização dos compradores e padronização 
do processo de compra. Ou ainda, descentralizada, onde cada unidade tem seu próprio setor de compras para atender às faltas locais. As vantagens consistem na proximidade dos fornecedores regionais, conhecimento mais aprofundado sobre as necessidades específicas de cada unidade da empresa e celeridade no processo de compras (CHIAVENATO, 2005).

De acordo com Viana (2006), a ação de comprar é realizada por algumas etapas. Primeiramente, é preciso saber o que, quanto e quando comprar. Em seguida, fazer uma análise dos fornecedores e suas competências técnicas, relacionando-os em uma lista para que ocorra uma disputa e seja escolhido o melhor. Além disso, deve-se acompanhar o produto desde o pedido até a entrega e posteriormente ao recebimento, controlar a qualidade e a quantidade.

Conforme Francischini e Gurgel (2009) resumem, o processo de compra normalmente acontece primeiramente realizando o cadastro de todos os fornecedores com informações capazes de mostrar se estão prestando um bom serviço, com produtos de qualidade, bons preços e boas formas de pagamento. Depois é solicitada uma cotação de preços para os mesmos e analisa-se qual proposta é a mais vantajosa. Assim que o fornecedor for escolhido, é feito o pedido de compra. Nesse momento, ele deverá enviar o material juntamente com sua nota fiscal. Em seguida, há o recebimento da mercadoria, conferindo as quantidades recebidas com as que estarão presentes na nota fiscal, além da observação da condição dos materiais, se os materiais estão em perfeito estado de fabricação ou se foram danificados no transporte. Após o recebimento é realizado o armazenamento dos produtos de forma adequada para que seja encaminhado para produção ou venda até que ele chegue ao seu destino e, finalmente, o controle de todo o estoque, que mostrará quando elaborar uma nova requisição de compras e quais as quantidades a serem compradas de cada item, começando novamente o ciclo de aquisição de materiais.

É notório que o custo da aquisição dos materiais e serviços influencia muito no valor total do produto. Uma empresa ficará profundamente frágil se adquirir produtos inadequados e não possuir um padrão no fluxo de suprimentos de materiais e serviços essenciais para a produção. Comprar com base em informações consistentes previne o excesso ou falta de materiais (GONÇALVES, 2004).

Outrora, os fornecedores eram considerados como adversários pelas empresas, visto que havia uma ideia de que eram sempre mal-intencionados, querendo apenas vender e lucrar à custa de alguns descuidos dos seus clientes. Para se prevenirem, as empresas realizavam várias cotações com o intuito de não serem enganadas, e inspecionavam bem a mercadoria quando as recebiam. Atualmente, o clima entre cliente e fornecedor é de mais confiança, onde todos ganham, isto é denominado como parceria, onde um depende do outro para prosperar (MARTINS; ALT, 2009). 
Conforme Gonçalves (2004), as grandes empresas possuem fornecedores que são considerados parceiros. Essa condição, garante a qualidade, a agilidade e a regularidade no fornecimento de materiais e dos serviços, resultando na sobrevivência da empresa no mercado.

Selecionar um bom fornecedor ajuda, também, na eficácia do departamento de compras, desde que leve em consideração sua qualidade, seus prazos de entrega, confiabilidade e principalmente seus preços, sendo fundamental para o desenvolvimento de todos (DIAS, 2009).

Essa relação entre cliente e fornecedor passa por quatro fases diferentes. A primeira é a abordagem convencional, que prioriza o preço onde aquele que possui mais poder acaba por determinar as condições e há desconfiança na qualidade dos produtos e serviços. Na próxima fase, a qualidade do produto é prioridade, resultando em um relacionamento mais duradouro e de confiança entre as partes. A terceira é a integração operacional que prioriza o controle dos processos, com o fornecedor participando do projeto do produto e do processamento. Já a última fase, é a integração estratégica, que é uma parceria nos negócios, em que o fornecedor colabora no desenvolvimento de materiais e métodos (MARTINS; ALT, 2009).

Segundo Francischini e Gurgel (2009), ter muitos fornecedores acarreta em vantagens como a possível concorrência de preços entre eles, certa segurança caso alguém não consiga entregar o produto, o poder de escolha da melhor proposta e a possibilidade de conseguir comprar de vários fornecedores quando há um aumento nas vendas, que, por vezes, apenas um não conseguiria atender a quantidade do pedido. Entretanto, com as parcerias, a relação se torna mais íntima. Nesse caso, pode haver trocas de informações diretamente entre os setores ou departamentos das duas empresas e problemas com a qualidade e prazos são capazes de serem resolvidos rapidamente. Além disso, há uma maior transparência nas negociações, segurança em relação à estabilidade dos preços fornecidos, previsão das quantidades produzidas pelo fornecedor e que estarão disponíveis para compra, melhor negociação de prioridades de suprimento, fornecimento de financiamento e equipamentos pelo comprador para produção de itens, colaboração para novos projetos e melhorias no processo de produção e no projeto do produto.

\subsection{Gestão de estoques}

De acordo com Dias (2009), a gestão de estoques tem por objetivo aprimorar o investimento, melhorando o uso eficiente dos recursos financeiros e diminuindo as necessidades de dinheiro investido em estoques.

Os estoques consomem capital de giro, que podem estar parados sem oferecer retorno, mas encontram-se disponíveis a qualquer momento. É por este 
motivo que se torna necessária a sua formação que deve ser acompanhada de gerenciamento que elabore níveis adequados para manter o equilíbrio entre o estoque e o consumo (VIANA, 2006).

Os materiais são armazenados em almoxarifados ou depósitos e há uma diferenciação, uma vez que o almoxarifado é responsável por armazenar as matérias-primas, enquanto os depósitos armazenam os produtos acabados, prontos para distribuição aos clientes. É importante que os produtos estocados estejam organizados para uma fácil localização e acesso, utilizando uma codificação, que geralmente é alfanumérica, para representar o local da estocagem. Esse conjunto de códigos deve mostrar o posicionamento de todo material do estoque, facilitando e agilizando as movimentações (DIAS, 2009).

Vários fatores melhoram a eficácia dos depósitos. A utilização cúbica e a acessibilidade permitem que os produtos não sejam armazenados apenas no chão, mas no espaço cúbico do depósito, mantendo um local para os corredores, balcões recebimento e entrega, bem como espaço de escritórios e áreas para a escolha e montagem dos pedidos. Outro fator é a localização do estoque, em que se agrupam itens de utilização semelhantes, de giro rápido, fisicamente semelhantes, devendo-se separar o estoque de trabalho da reserva. O último fator deve ser a escolha e montagem do pedido. Devido à mão de obra utilizada para essa ação, é preciso organizar-se a fim de atender todos os clientes com o mínimo de custo (ARNOLD, 2006).

Há dois sistemas de localização de materiais. O primeiro é a estocagem fixa, onde cada material tem um lugar estabelecido para sua armazenagem. $\mathrm{O}$ problema é que pode ocorrer desperdício de espaços. Já na estocagem livre, os produtos não possuem local fixo para armazenagem e vão ocupando os espaços vazios disponíveis no depósito. Nesse sistema pode correr o risco de não encontrar o material, por isso é fundamental um controle rigoroso do endereçamento dos produtos (DIAS, 2009).

Os estoques podem ser classificados, segundo Arnold (2006), em matérias-primas, produtos em processo, produtos acabados, estoques de distribuição e suprimentos de manutenção, de reparo e de operação. As matérias-primas são os itens necessários para a fabricação dos produtos. Já os produtos em processo são as matérias-primas que estão em produção. Os produtos acabados são os estoques que foram finalizados e estão prontos para a venda. Os estoques de distribuição são os produtos acabados que já se encontram no sistema para a venda. E os suprimentos de manutenção, reparo e operação são os itens utilizados para auxiliar na produção, ou seja, não se tornam parte do produto.

Conforme Chiavenato (2005), para controlar e conhecer os estoques é essencial que a organização utilize o fichário de estoque e a classificação $\mathrm{ABC}$, que são duas ferramentas administrativas básicas que hoje em dia usam platafor- 
ma eletrônica. O primeiro é composto por dados e documentos que informam, analisam e controlam os estoques. Já o segundo controla o estoque considerando que o maior investimento está em poucos itens.

O principal objetivo da análise $\mathrm{ABC}$ é identificar os itens de maior valor de demanda e sobre eles exercer uma gestão bem mais refinada, especialmente porque representam altos valores de investimentos e seu controle mais apurado vai permitir grandes reduções nos custos dos estoques (GONÇALVES, 2004, p. 136).

A classificação $\mathrm{ABC}$ é muito significativa para o administrador, pois possibilita que ele verifique os itens que merecem mais atenção e um devido tratamento. A classe A é o conjunto mais importante, assim merece um tratamento especial, sendo composta por poucos itens, mas que representam um grande valor do estoque. Em seguida, a classe B é o conjunto intermediário e possui uma relativa importância no valor global. E a classe $\mathrm{C}$ é um grupo de muitos itens, mas com pouca importância em valor (DIAS, 2009).

Segundo Arnold (2006), no sistema de duas gavetas há uma quantidade que foi determinada para a reposição de cada item e que fica em um local separado, uma segunda gaveta, que não é utilizado até que o estoque principal acabe. Quando é preciso utilizá-lo, o setor de compras é alertado para realizar a reposição. É a forma mais simples de controlar o estoque, sendo indicado para os itens da classe $\mathrm{C}$.

O sistema dos máximos-mínimos determina o consumo previsto para o item desejado e fixa seu período. Além de calcular o ponto de pedido de acordo com o tempo de reposição do item pelo fornecedor, calcular os estoques mínimos e máximos e os lotes de compras. Sua vantagem é a automatização do processo de reposição e abrange os itens de todas as classes A, B e C (DIAS, 2009).

Os métodos eficazes de gestão de estoque podem reduzir o inventário dos produtos resultando em níveis de estoques adequados e permitindo que se minimize o investimento total em estoques ao mesmo tempo em que se adota um perfil com menor risco de ter excesso ou falta de materiais. Esse sistema se baseia em um estoque mínimo para prevenir eventuais demandas acima do normal ou atrasos na entrega das mercadorias (SCALA; RAJGOPAL; NEEDY, 2013).

Segundo Arnold (2006), o planejamento das necessidades de materiais possui dois objetivos principais: determinar exigências, ou seja, definir os componentes essenciais para atender os produtos que serão produzidos e calcular o tempo em que os componentes devem estar disponíveis e também manter as prioridades atualizadas, pois, podem ocorrer várias mudanças, como o surgimen- 
to de mais clientes ou alteração das encomendas.

O MRP é um sistema que aponta as quantidades essenciais dos materiais no tempo correto para utilizá-los na fabricação dos produtos finais. Para realizar esse planejamento há elementos que interagem com o MRP e o tornam eficaz. Primeiramente, o programa-mestre de produção, os pedidos e as demandas são quem orienta o MRP, já que informam quais os componentes e quando serão agregados ao produto final. Em seguida, a lista de materiais possui as quantidades certas de componentes, matérias-primas e sub-rotinas que ocasionarão a confecção do produto final. No registro de inventários é possível identificar o posicionamento dos estoques e pedidos em aberto. Já no programa MRP a demanda do produto final é transformada em necessidades brutas para cada item. Assim, com as informações do registro de inventários, são calculadas as quantidades líquidas necessárias para a produção e há os relatórios e dados de saída que são úteis para gerenciar o processo logístico e de manufatura (DIAS, 2009).

Um problema que aparece nesse processo de gestão de estoques é a inexatidão das quantidades registradas nos sistemas de estoques quando estes dados são comparados com o estoque real. Arnold (2006) apresenta algumas causas que podem gerar esses erros como a retirada de materiais sem autorização, depósito sem segurança, pessoal mal treinado, mau registro das movimentações devido a falha na contagem, movimentações não registradas, dentre outros, além da falta de capacitação para realizar auditorias. No entanto, estas falhas podem ser minimizadas pela boa gestão e também pelos sistemas informatizados.

\subsection{Custos de estoque}

É essencial se atentar aos custos que o estoque gera, pois as empresas precisam ter um preço menor do que o dos seus concorrentes para se manterem competitivas no mercado. Visto isso, Francischini e Gurgel (2009) desmembram o custo de estoque em quatro partes. Primeiramente, o custo de aquisição, que nada mais é do que o valor que a empresa pagou para adquirir determinado produto. Saber negociar, nesse momento, poderá diminuir o preço pago na mercadoria. O segundo é o custo de armazenagem que consiste nos custos para guardar o estoque. Em seguida aparece o custo de pedido que trata dos custos administrativos e operacionais da área de compras. Além do quarto item que envolve o custo de falta de um item em estoque. Essa falta gera grandes prejuízos a empresa, já que pode parar uma linha de produção inteira.

Existem ainda duas variáveis que influenciam no aumento desses custos que são a quantidade e o tempo em estoque. Grandes estoques aumentam o uso de pessoal, energia, espaço e equipamentos, e quanto maior o tempo que o material permanece em estoque, maiores são os custos das empresas que, consequentemente, anexam aos preços de venda dos produtos devido ao capital de 
giro investido neles. Por isso, o planejamento e controle dos estoques de forma aprimorada pode reduzir os custos das empresas (DIAS, 2009).

Conforme Pozo (2002), a avaliação do estoque é importante para assegurar que o valor investido seja o menor possível e esteja de acordo com a política da empresa, garantindo que a valorização do estoque reflita seu conteúdo e fazendo com que o valor desse capital se torne uma ferramenta de tomada de decisões para evitar desperdícios como obsolescência, roubos, extravios entre outros. Por isso, a avaliação financeira do estoque deve ser feita com cautela para resultar em informações exatas e atuais dos produtos, com base nos preços de cada item a fim de se conhecer o seu valor e quantidade por tipos de itens ou na sua totalidade.

O estoque pode ser avaliado pelos métodos de custo médio, PEPS ou FIFO e UEPS ou LIFO. O custo médio é o mais utilizado e é calculado por meio da média entre a soma do custo total e a soma das quantidades, resultando em um valor médio por unidade. Já no PEPS (Primeiro a Entrar, Primeiro a Sair) ou FIFO (First In, First Out), cada lote de compra é controlado separadamente, sendo que o material que entrou primeiro, sai primeiro e com o seu respectivo preço unitário. No método UEPS (Último a Entrar, Primeiro a Sair) ou LIFO (Last In, First Out) é o inverso do PEPS, mas este não é permitido pela Resolução CFC $\mathrm{n}^{\mathrm{o}}$ 1.255/09, que aprova a Norma Brasileira de Contabilidade (NBC) T 19.41. Assim, os últimos produtos a entrar são os primeiros a sair com seu respectivo custo unitário (FRANCISCHINI; GURGEL, 2009).

\subsection{Logística}

Segundo Viana (2006), a logística é uma operação encarregada por garantir suprimento e a correta distribuição dos produtos, planejando, coordenando e executando todo o processo, com a finalidade de diminuir os custos e aumentar a competitividade da empresa. É responsabilidade dos gestores de logística realizar o planejamento, a operação e o controle de toda movimentação de mercadorias e informações a elas referentes. Ela começa quando o cliente decide transformar um desejo em realidade por meio de um pedido ou compra (MARTINS; ALT, 2009).

Ching (2001) divide as atividades da logística definindo-as em primárias e secundárias. As atividades primárias são essenciais para a logística e constituem seu maior custo. São os transportes, a gestão de estoques e o processamento de pedidos. Já as atividades secundárias servem de apoio às atividades primárias da logística. Nessas atividades estão contidas a armazenagem, o manuseio de materiais, a embalagem de proteção, a programação de produtos e a manutenção de informação.

Dependendo dos produtos/serviços ofertados por uma empresa, do es- 
paço, do processo produtivo e da necessidade de movimentação de materiais, são necessários equipamentos para realizar essa movimentação. Chiavenato (2005) aponta os principais tipos de equipamentos, sendo um deles os veículos industriais, que são mais versáteis e não possuem limites fixos de movimentação, como as carretas, carrinhos, empilhadeiras, tratores e trailers. Em seguida, há os transportadores contínuos, utilizados para a movimentação constante e ininterrupta dos materiais entre pontos fixados, como, por exemplo, as esteiras transportadoras. Existem também os guindastes, talhas e elevadores destinados às áreas restritas e limitadas. Já os contêineres e estruturas de suporte são tidos como equipamentos auxiliares, pois dependem de outros para se deslocarem. Além dos equipamentos diversos e plataformas que também auxiliam na colocação e posicionamento para pequenas movimentações de materiais.

A logística é vital para a empresa, uma vez que busca mais eficácia na distribuição de mercadorias para seus clientes, considerando o planejamento, a organização e o controle das movimentações e da armazenagem para facilitar o fluxo dos materiais do começo ao fim do processo que pode ser considerado a entrega do produto acabado ao cliente (CHING, 2001).

\section{METODOLOGIA}

A presente pesquisa possui caráter descritivo, pois, por meio dela foi possível descrever como microempresas do município de Alto Paraná realizam o controle dos seus estoques. A pesquisa descritiva procura descrever características de alguma população, fenômeno ou estabelecer relações entre os dados e práticas em análise (GIL, 2002).

Nos meses de abril e maio do ano de 2019 , foram realizadas entrevistas qualitativas por meio de questionário composto por 23 perguntas dissertativas com participação dos gestores de 6 microempresas de diversos ramos de atividade em seus respectivos estabelecimentos. A partir das colaborações dos participantes, ao final, procurou-se agrupar as respostas por semelhança. Segundo Marconi e Lakatos (2010), a entrevista qualitativa é realizada por conversa espontânea, mas profunda, entre entrevistador e entrevistado a fim de se obter respostas sobre o tema escolhido.

A empresa A, atua na área de peças para veículos, possui 9 funcionários e foi fundada em 2001. A empresa B, realiza vendas de móveis e eletrodomésticos, tem 8 funcionários e foi fundada em 2003. Já as empresas C e D atuam na venda de calçados e confecções, sendo a primeira com 4 funcionários e fundada em 2002, e a segunda com 5 funcionários e fundada em 2016. E por fim, as empresas $\mathrm{E}$ e $\mathrm{F}$ atuam no ramo de supermercados, a primeira conta com 8 funcionários e foi fundada em 1964, e a segunda com 5 funcionários e fundada em 2010. 
Mediante as respostas obtidas foi possível comparar por agrupamento de semelhanças quais ações em relação à gestão de estoque são mais comuns entre as microempresas de Alto Paraná que é uma cidade de pequeno porte. Segundo Netto (2008), o método comparativo é realizado para evidenciar semelhanças ou diferenças, por meio de comparações entre elementos e, dessa maneira, na sequência, foram analisadas as semelhanças relatadas para se traçar o perfil de gestão de materiais destas organizações.

\section{RESULTADOS E DISCUSSÃO}

Analisando as respostas das empresas entrevistadas, foi observado que todas possuem considerável nível de controle de estoque, pois lançam suas entradas e saídas em sistemas informatizados que cadastram os produtos com suas respectivas informações, como código interno, códigos de barras, preço de custo, preço de venda, entre outros dados. Por meio deles as empresas conseguem emitir relatórios que os ajudam a tomar decisões sobre a gestão de estoques, utilizando principalmente o relatório de vendas do último mês. Conforme citado por Dias (2009), é importante uma boa gestão de estoques para conseguir aprimorar o investimento, melhorando o uso dos recursos financeiros e diminuindo o valor investido no estoque para manter sempre o capital em circulação e não o deixar parado.

Verificou-se também que todas as microempresas lançam suas notas fiscais de entrada manualmente, somente utilizam o XML quando é oportuno. De acordo com Lima e Carvalho (2005) XML significa extensible markup language, ou seja, linguagem extensível de marcação, que permite a construção de documentos legíveis para seres humanos e que podem ser facilmente tratados por máquinas. A importação do XML tornaria o processo de lançamento de entrada mais rápido e seguro, trazendo informações mais exatas. Isto posto, também foi verificado que algumas empresas estão buscando as melhorias tecnológicas necessárias para aperfeiçoar o seu método de lançamento de informações sobre seus materiais.

No que concerne ao cálculo dos custos dos produtos, a maioria das microempresas o efetuam por meio do custo médio entre os preços antigos e os novos, enquanto, a minoria utiliza os preços novos como referência ou esperam zerar a mercadoria antiga para depois utilizar o novo valor. Esse cálculo é correlato com a teoria exposta por Francischini e Gurgel (2009) em que se explica que o custo médio é calculado pela divisão entre a soma do custo total e a soma das quantidades, que resultam no valor médio unitário.

Foi observado que a maioria das microempresas realiza os seus lançamentos de entrada e saída quando elas ocorrem propriamente, ou seja, não há 
espera entre a movimentação e o lançamento da movimentação. No entanto, a minoria somente lança as entradas certo tempo depois do ocorrido na prática. É considerável ressaltar que o lançamento deve ser feito logo no momento da sua ocorrência, pois, conforme exposto por Arnold (2006), um grande problema da opção a posteriori é o equívoco das quantidades registradas nos sistemas de estoques que podem ser causados pela falta de lançamento. Assim, se lançadas já no momento da ocorrência, as quantidades estarão sempre atualizadas, ainda que esse processo demande de mais organização.

Sobre as maiores dificuldades na gestão do estoque, houve várias situações identificadas. A maioria das empresas pesquisadas acredita que seu maior problema são os registros que precisam ser realizados no sistema e que muitas vezes não são feitos ou são lançados de forma equivocada. Dessa forma, verifica-se que é preciso uma maior atenção e treinamento para os funcionários responsáveis, reduzindo a quantidade de erros e demora. No caso específico das microempresas do ramo do mercado foi verificado que controlar o vencimento dos produtos é um grande desafio, mas que pode ser solucionado realizando-se uma gestão por meio de sistemas de informação que colaborem para o controle destas datas. Resolver estes problemas é primordial visto que uma boa administração de materiais aumenta as vantagens competitivas da empresa, já que reduz custos (GONÇALVES, 2004).

Conforme exposto pela teoria de Pozo (2002), é importante avaliar o estoque para garantir que o valor investido seja o menor possível. Diante do exposto, foi observado que as microempresas têm conhecimento do valor individual e total dos custos das suas mercadorias por meio dos seus sistemas e algumas possuem um valor de estoque significativamente alto, entretanto, ainda perdem produtos por perda de validade e também não possuem um processo de compras especializado e baseado nos dados dos seus sistemas. É notório que ainda é necessário um aprimoramento de gestão para que mantenham uma quantidade de estoque que atenda à demanda de forma mais equilibrada para não comprometer e maximizar as suas finanças. As perdas apresentadas são causadas pela validade dos produtos e em outros casos, defeitos, mas normalmente seus fornecedores realizam as trocas destas mercadorias com baixo custo, mesmo assim, esta situação continua a ser inadequada.

Em relação à armazenagem do estoque, todas as microempresas possuem um local apropriado e fixo para seus produtos que são comprados prontos. Conforme apresentado por Arnold (2006), os estoques podem ser classificados em matérias-primas, produtos em processo, produtos acabados, estoques de distribuição e suprimentos de manutenção, de reparo e de operação. Os mercados deixam seus itens apenas nas prateleiras, pois não possuem um depósito para manter estoque. Contudo, eles são organizados por setores, o que facilita a loca- 
lização. Já os comércios de calçados organizam por marca, modelo e numeração. E os demais utilizam uma codificação numérica crescente para localizar seus produtos no estoque. Paralelo ao pensamento apresentado por Dias (2009) que declara que é importante a organização física dos produtos para que sejam facilmente encontrados.

Foi constatado que as microempresas pesquisadas estão com custos de estoque relativamente altos, já que há falta de alguns itens e outros em excesso, sendo que o correto é comprar a quantidade ideal, mas assim que percebem o problema de falta de algum produto, realizam o pedido para repor e conseguir atender a demanda. As compras são realizadas por meio de vendedores que vão até as lojas, por e-mail ou por telefone, sempre que precisam repor mercadorias e os microempreendedores participantes da pesquisa não utilizam um ciclo pré-determinado para fazerem os pedidos. Segundo Dias (2009) realizar um bom controle do estoque contribui para realizar compras na quantidade correta, e isso ajuda a diminuir os custos.

As quantidades dos produtos a serem comprados são previstas e definidas na maioria das empresas por meio de relatórios dos sistemas com base nas últimas compras e vendas, sendo que a minoria julga pedir a quantidade mínima necessária para manter o estoque baixo, mas eficaz. Na maior parte das empresas há várias pessoas envolvidas no processo de compra, onde uma faz a compra, outra recebe e outra é responsável pelo armazenamento dos produtos. Elas acreditam que com a divisão das funções o processo se torna mais rápido, visto que cada um sabe exatamente o que precisa ser feito. Apenas uma empresa tem uma única pessoa que faz tudo. A maioria realiza contagem de estoque anualmente para corrigir possíveis erros na quantidade real e a quantidade do sistema, o que ajuda na emissão de relatórios corretos para tomada de decisões sobre as compras, no entanto, devido ao logo intervalo pode gerar acúmulo de erros prejudicando o controle. Estas ações estão em consonância com a teoria apresentada por Arnold (2006) que mostra possíveis causas de erros no estoque. Todavia, algumas empresas não fazem esse processo que é extremamente importante, alegando não possuírem tempo, como no caso das empresas analisadas.

Foi observado que as microempresas obtêm uma previsão da demanda futura pelos relatórios de vendas de meses anteriores emitidos pelo sistema. Paralelo à teoria de Arnold (2006), as técnicas de previsão podem ser classificadas em qualitativas, extrínsecas e intrínsecas. As microempresas entrevistadas utilizam as técnicas intrínsecas que usam dados históricos, registrados por um sistema, onde se acredita que o que aconteceu no passado, acontecerá no futuro. Dessa maneira conseguem se preparar comprando mais produtos dentre os que possuem uma procura maior. Porém, há períodos de sazonalidade em que as vendas crescem e, para atender toda essa demanda, a maioria aumenta seus 
estoques. Somente uma empresa não consegue se preparar e acaba apresentando falta de produtos, contudo, está estudando maneiras de melhorar suas compras. De acordo com Gonçalves (2004) acredita-se que determinar a demanda futura é essencial elaboração de um plano de trabalho para saber se a empresa possui equipamentos, recursos financeiros, mão de obra e as quantidades necessárias para atender tal demanda.

A maioria dos gestores afirmou realizar cotações frequentes, ter uma boa relação com os fornecedores e os consideram como parceiros ao invés de oportunistas. Também têm a visão de que esta postura é essencial para economizar por meio da redução de custos com os produtos e ficar por dentro das novidades. Em consonância com o exposto por Gonçalves (2004), pode ser observado que as empresas consideram seus fornecedores como parceiros, obtendo mais qualidade, agilidade e regularidade no fornecimento de materiais, em que ambas as partes ganham, conseguindo se manter no mercado.

Verificou-se que a maior parte das empresas efetua o transporte de suas mercadorias dentro do seu estabelecimento manualmente sem contar com ferramentas de transporte especializadas ou informatizadas. Somente duas utilizam carrinhos de carga, mas há de se considerar que devido ao tamanho reduzido de algumas empresas entrevistadas, não há necessidade de muitos equipamentos para transporte, pois, a sua utilização se tornaria inviável financeiramente, no entanto, alguns meios de transporte mais simples poderiam agilizar o processo de movimentação das mercadorias.

Como estratégia de mercado, as empresas utilizam a oferta de conveniência ao cliente realizando entregas de produtos nos domicílios ou outras empresas da cidade, seja de carro ou moto, tornando mais cômodo e prático para seus clientes. Conforme Ching (2001), essa logística é muito importante para a empresa, pois busca uma melhor distribuição de mercadorias para os clientes, planejando, organizando e controlando o fluxo e armazenagem dos produtos.

Observando os aspectos analisados, nota-se que a maioria das empresas realiza o controle de materiais, mas não sabem ou tem real interesse de interpretar os relatórios que os seus sistemas emitem, condição que permitiria tomar decisões mais corretas sobre o estoque. Todas percebem e estão cientes sobre a maior parte dos seus pontos fracos relativos à gestão de materiais, no entanto, não conseguem ou se esforçam para resolver, ainda assim, gostariam de melhorar os seus processos para obter melhor desempenho organizacional.

\section{CONSIDERAÇÕES FINAIS}

Mediante as análises e discussões dos resultados deste estudo, pode-se afirmar que a pesquisa atingiu o objetivo proposto, que era analisar os processos, 
ferramentas e ações de administração de materiais utilizadas por microempresas onde foi possível conhecer a configuração das empresas analisadas. Ao final de tudo foi verificado que as empresas pesquisadas utilizam os métodos e ferramentas preconizados como adequados pelas teorias abordadas de forma modesta, pois, alguns podem ser adotados para gerar maior eficácia da gestão dos recursos materiais.

Foi constatado que a maioria das empresas possui um sistema de informação que contém a função de gestão de materiais e que também efetuam os lançamentos de entrada e saída, porém, acabam utilizando o sistema apenas para controlar o estoque e fazer a sua reposição sem maiores pretensões. Foi verificado que muitas empresas ainda contém em seus estoques alguns produtos em maior quantidade que o necessário. Os gestores poderiam agir para reduzir este estoque de materiais desnecessário que compromete o capital de giro por meio de promoções destes produtos específicos e com compras mais racionais, com base nas informações dos seus sistemas, desta forma, não ficariam com investimentos em estoques desnecessários.

Em todas as empresas analisadas foi verificado que poderiam utilizar a importação do XML das notas fiscais de entrada para tornar o processo de lançamento mais rápido e exato. Para se aumentar a eficácia organizacional, existe a necessidade de se adotar medidas para diminuir a quantidade e valor dos estoques que, de modo geral, encontram-se relativamente altos.

As ferramentas que utilizam para o controle físico e movimentação de produtos são simples e pouco eficazes, se for levado em consideração às possibilidades que a tecnologia atual permite, estas empresas poderiam utilizar outras mais eficazes que resultariam em controles do estoque e ações mais eficazes para gerar a economia de custos via racionalização dos estoques, no entanto, é compreensível que devido aos seus portes mais modestos e localização em cidade com menor concorrência e menos especializada, que não se sintam estimuladas a tal nível de aprimoramento, mas há de se pensar que cada melhoria na gestão pode se converter em maior desempenho, o que pode ser traduzir em lucro.

No caso das duas empresas do segmento de supermercados, onde foram relatadas inconsistências entre quantidade do sistema e a quantidade real dos estoques, poderia se adotar a prática de lançar todas as entradas e saídas no momento em que ocorrem, já que deixaria o estoque sempre com a quantidade correta, além de melhorarem o controle do vencimento dos produtos e evitarem furtos. As empresas poderiam fazer a contagem dos seus estoques mais vezes ao ano para diminuir os erros nas quantidades e conseguir definir quanto deve ser comprado ou também poderiam adotar um controle eletrônico de mercadorias, o que evitaria uso de tempo de funcionários para esta ação. As empresas também poderiam, com base na análise dos dados do seu estoque de períodos anteriores, 
planejarem uma melhor delimitação de estoque necessário para os períodos futuros, em caso de sazonalidade de consumo detectada no sistema, observando relatórios e comprando para conseguir atender a demanda na quantidade e variedade ideal, levando a estoques mais baixos possíveis. Esse direcionamento poderia reduzir os custos decorrentes dele.

Ao final, o que se verifica é que as empresas estudadas possuem um nível relativamente simples, mas organizado de gerir os seus materiais. Apesar das possibilidades de desenvolvimento apresentadas acima, as empresas conseguem manter-se por meio da configuração adotada, mas é preciso destacar que existem processos, ferramentas e ações de administração de materiais mais eficazes que poderiam ser adotadas o que poderia levar a um maior desempenho organizacional.

Esta pesquisa deixa como recomendação a realização de novos estudos sobre a gestão de materiais em microempresas de outras cidades, do mesmo porte de Alto Paraná, para que se possa complementar e comparar com os resultados deste estudo, contribuindo com novas informações a respeito do que foi pesquisado e também para refinar o conhecimento sobre a gestão de materiais de empresas com esta configuração.

\section{REFERÊNCIAS}

ARNOLD, J. R. T. Administração de materiais: uma introdução. São Paulo: Atlas, 2006.

CHIAVENATO, Idalberto. Administração de materiais: uma abordagem introdutória. 3. ed. Rio de Janeiro: Elsevier, 2005.

CHING, H. Y. Gestão de estoques na cadeia de logística integrada. 2. ed. São Paulo: Atlas, 2001.

DIAS, M. A. P. Administração de materiais: princípios, conceitos e gestão. 6 . ed. São Paulo: Atlas, 2009.

FRANCISCHINI, P. G.; GURGEL, F. A. Administração de materiais e do patrimônio. São Paulo: Cengage Learning, 2009.

GIL, A. C. Como elaborar projetos de pesquisa. 4. ed. São Paulo: Atlas, 2002.

GONÇALVES, P. S. Administração de materiais: obtendo vantagens competitivas. Rio de Janeiro: Elsevier, 2004. 
LiMA, J. C.; CARVAlHO, C. L. Extensible Markup Language (XML). Relatório técnico - RT-INF_002-05. Junho, 2005. Disponível: http://www. inf.ufg.br/sites/default/files/uploads/relatorios-tecnicos/RT-INF_002-05.pdf. Acesso em: 25 abr. 2019.

MARCONI, M. A.; LAKATOS, E. M. Fundamentos da metodologia científica. 7. ed. São Paulo: Atlas, 2010.

MARTINS, P. G.; ALT, P. R. C. Administração de materiais e recursos patrimoniais. 3. ed. São Paulo: Saraiva, 2009.

OLIVEIRA NETTO, A. A. de. Metodologia da pesquisa científica guia prático para apresentação de trabalhos acadêmicos. 3. ed. Florianópolis: Visual Books, 2008.

SCALA, N. M.; RAJGOPAL, J.; NEEDY, K. L. A Base Inventory Management System for Intermittent Spare Parts. Military Operations Research, v. 18, n. 3 p. 63-77, 2013. Disponível em: https://www.jstor.org/ stable/24838481?seq=1\#page_scan_tab_contents. Acesso em: 01 ago. 2019.

POZO, H. Administração de recursos materiais e patrimoniais: uma abordagem logística. 2. ed. São Paulo: Atlas, 2002.

VIANA, J. J. Administração de materiais: um enfoque prático. São Paulo: Atlas, 2006. 